\title{
CITY PROJECT BY RIVER FRONTS ON BEHALF OF UNIVERSITY INTERNATIONAL RESEARCH
}

\author{
A. Virtudes, A. Debicka, L. Janik, M. Barwinska, N. Choinacka \\ University of Beira Interior (PORTUGAL)
}

\begin{abstract}
Universities are dealing with strategies in order to improve their performances in terms of ranking classification, struggling for a good position. At the spatial planning and urban design domains the river fronts are very challenging territories to deal with, because they are sensitive areas, not only in environmental terms but also considering the requirements of the urban continuity. Urban projects for the places of contact in between the urban fabric and rivers are mainly focused on building issues and urban development questions, rather than of ecological approaches encouraging the contact of inhabitants with nature. Therefore, this research presents solutions of rethinking the territories of contact in between the urban fabric and the river water fronts, having as pivotal concern the ecological solutions. These urban projects are focused on the requalification solutions in order to ensure a better urban continuity from the buildings to the water front. The strategy is driven by the river activities, nautical sports, low density buildings, preservation of local heritage and paths for pedestrians.
\end{abstract}

The case study is a quiet town in the central region of Portugal, well known by its thermal baths, which are coming from the roman times. Every year, the city of São Pedro do Sul is visited by many tourists, looking for a very pleasant place, allowing them to improve their health condition going to the thermal baths, or the contact with nature going to the Vouga river water front. This is a city plenty of greenery, high natural potential, no pollution, and where the majority of dwellings are single houses. The main architectural landmark of the case study area is the old train station, a building from the $19^{\text {th }}$ century. In fact, since a long time ago, there are no more trains arriving to this city. Recently, the train track line was converted into an ecological corridor for pedestrians and bicycles. Besides of this effort, the place remains waiting for an urban rehabilitation opportunity as a whole, with several urban voids, buildings in bad status of conservation, car parking with no planning or a lack of functional diversity. Its huge potential regarding the presence of the river water front is, consequently, not preserved nor enhanced. In this sense, there was an international research, on behalf of the Urban Planning Unit at the Master Degree in Architecture at the University of Beira Interior, resulting from an agreement with the Municipality of São Pedro do Sul. The urban project solutions were proposed in this academic environment comprising several teams of international students, not only coming from Portugal, but also from Greece, Brazil, Slovakia, Lithuania and Poland. There was a competition and monetary prizes to the best urban projects, sponsored by the city hall. This was a motivation for students along to the project process. The conclusions show that all the solutions are proposing strategies to preserve and to enhance the ecological identity of the place. Thus, this article will present the contents, options and solutions of the second best urban project, which was designed by a team of international students from Poland. This experience is an example of a key strategy in the internationalization process of the university.

Keywords: City project, River fronts, Urban fabric, International team, São Pedro do Sul, Vouga water front.

\section{INTRODUCTION}

São Pedro do Sul is a city in Portugal with a central position in the country, belonging to the region of Viseu (Figure 1). It has a long history strongly began in Roman times. Its most important aspect are the thermal baths, very well known all over the country. At the University of Beira Interior in Covilhã, Portugal, for the academic year of 2017/2018 at the Urban Planning Unit in Architecture Studies, the main task was to design a proposal of development for the area of the train station surroundings in São Pedro do Sul at the Vouga river banks. This is a favourable place, where is possible to create public spaces for residents and tourists. During the designing process, there was the need of facing many aspects. For example, taking in account the characteristics of the place, like the river, the main square, the historical building of the train station or the requirement of connection all parts together to give a space for everyone. Thus, the most important aspect of this project is hiding roads behind new pavilions, and the location of projected buildings in such a way to not obscure the natural landscape of 
the river and to not create a competition of architectural styles of the train station. Just use it. While planning those kind of places, the major aspect was for this group to focus on which parts of a certain space could be used and adapted. The main goals were greening the space and creating a meeting place, using the river for kayak trips and to connect the opposite river bank with the whole area, through the bridge with bicycle and walking paths. This was the main purpose of urban design proposal for the case study area in São Pedro do Sul.

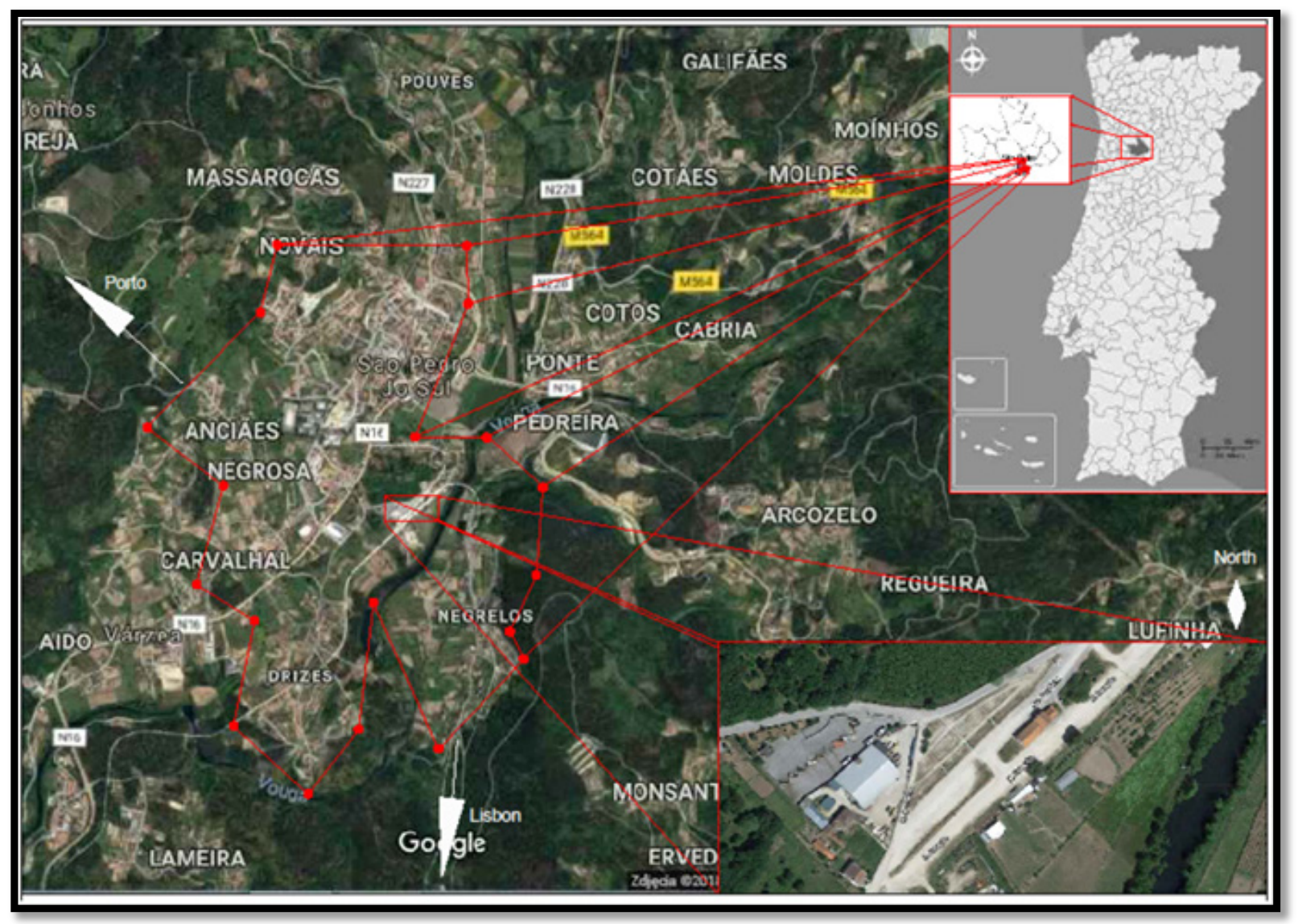

Figure 1. Localization of the case study area: Train station surroundings in São Pedro do Sul, Portugal.

\section{METHODOLOGY}

The case study area is a place located over Vouga river. Therefore, in methodological terms, regarding the urban design process there is the need of ensuring the continuity of the urban fabric with the water front and to use following elements, which are part of the area: to improve the use of the train station building, to rethink the granite stone retaining wall, to qualify the Vouga river banks and the view of the mountains, to create car parking, to improve the bridge as a connection icon, to expand the green spaces, to propose housing, network of roads, sidewalks and bike paths (Figure 2 and Figure 3). There is the need of highlight the main natural element, which is Vouga river, and the most relevant historical landmark, the nineteen-century train station building. In this sense, the project will keep smoothness between buildings and river, dictating a streamlined shape of architecture. The methodological approach has to analyse the geometry of roads, sidewalks and characteristic points, creating a logical and strategically coherent urban place as a whole. The good or strong aspects of the case study area, are the following (Table 1): the attractive landscape, the easy access to the river, the existence of a lot of green spaces, or the closeness to the city centre at a walkable distance, which kept existing character of this place. The architecture that will be proposed should be adapted to the surroundings terrain, transforming some building into grounds. Buildings mostly connects with riverbank, accentuating the river water front instead to cover it. Thus, the project will be focused not only on the river, but also on the main building like the train station and to planning the space around. The proposal will be driven by two main buildings with lot of activities, such as a restaurant, a common 
space for everybody, a conference room, an information point, a gym, or a place for children. These buildings will be supported on the granite existing retaining wall.

Greenery is another very important aspect to be considered at the urban design project, that is why buildings will be covered with green roofs. Therefore, people can walk on the roofs, from where there is a beautiful view over the surrounding landscape to the river and to the mountain. According to some authors [1], green surfaces including green roofs have been rarely used as elements of urban design, and the urban fabric composition, either in new urbanizations or in the rehabilitation of historical places. Thus, this proposal will be considered has an innovation regarding the features of São Pedro do Sul. Near to the main buildings there will be the train station and rent housing allowing to rent bikes and kayaks as well for river activities. Another aspect of the urban design methodology is to create a central square for cultural and local community events. Therefore, the road will be crossing the area via underground. Thanks to this short of solutions, the case study area will be concerned about soft mobility for cycling and pedestrians. A lot of walking paths and cycle paths will run along to the area. An iconic element of the project will be the new bridge for pedestrian and cyclists. Streets will be organized and a new car park will be designed. Finally, the most complex task of this urban project was to develop a strategy able to reinforce the contact in between urban fabric and water front. Thus, this solution will try to create a smooth connection, which will join the river with the city. Vouga river will be a matching part of the city and attractive place for its inhabitants and visitors.

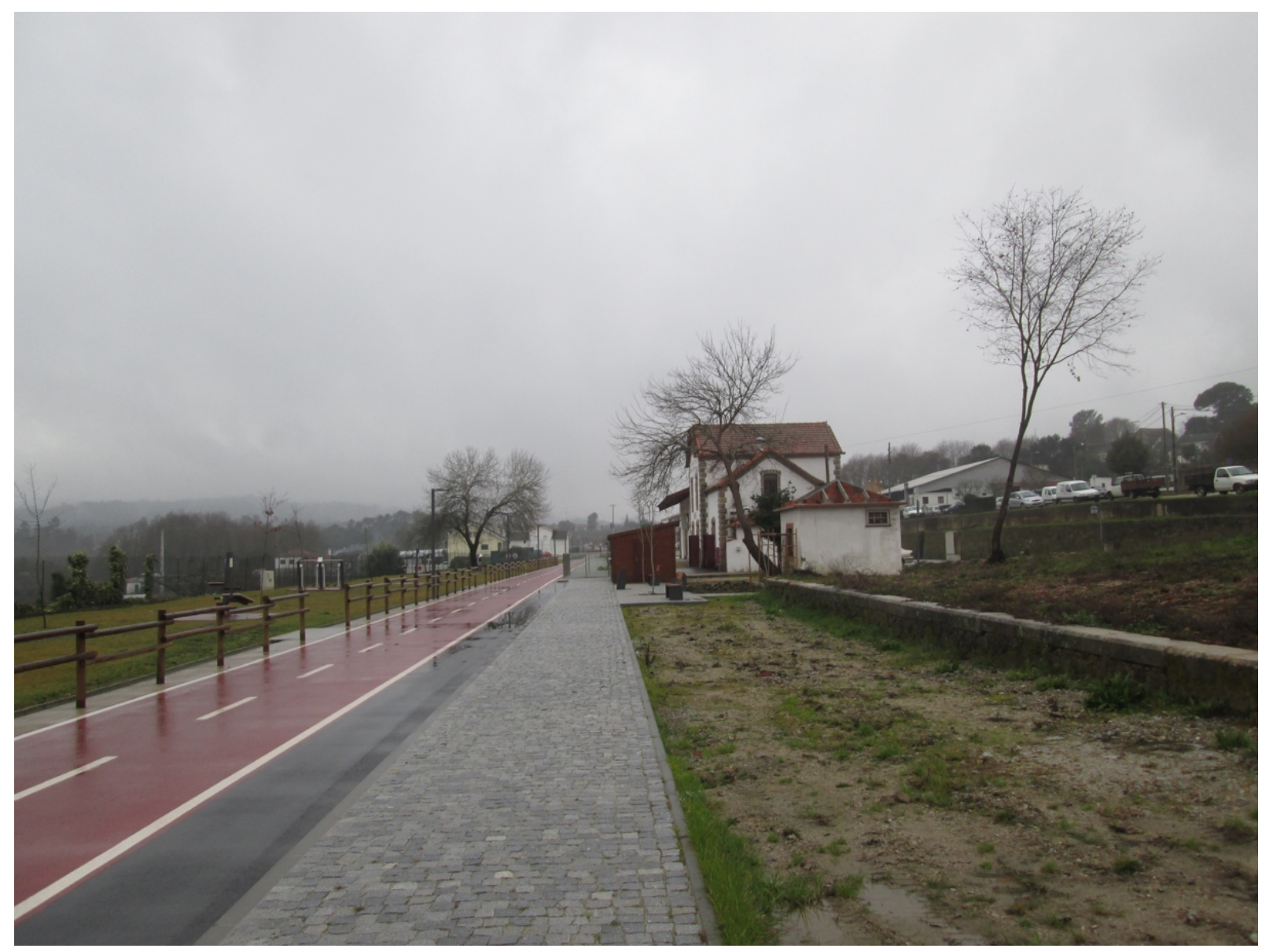

Figure 2. Cycling path and the nineteen-century train station building in São Pedro do Sul, Portugal. 


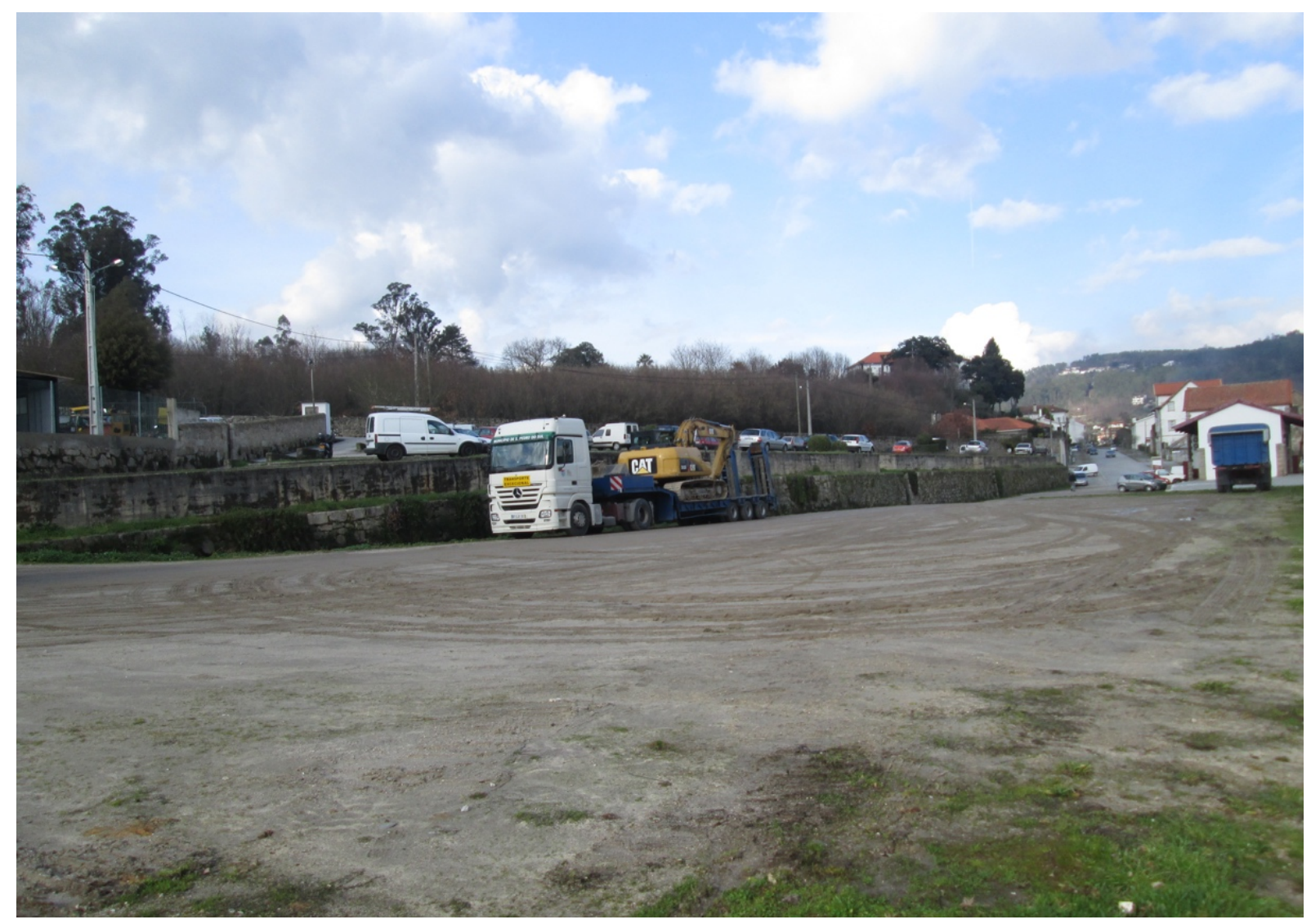

Figure 3. Case study area: two levels of the terrain and the granite retaining wall - Train station surroundings in São Pedro do Sul, Portugal.

Table 1. Identification of the weak and strong aspects of the case study area, São Pedro do Sul (Portugal).

\begin{tabular}{|c|c|}
\hline Weak aspects & Strong aspects \\
\hline lack of services & attractive landscape \\
\hline unattractive shape of plots & access to the river \\
\hline multi-level area & a lot of green areas \\
\hline bad access to public transport & close to the city centre \\
\hline unfavourable ground conditions & unlimited access to the daylight \\
\hline the need to organize the roads & lack of noise \\
\hline favourable localization relative to the country & safe neighbourhood \\
\hline strong wind due to open space & lack of high buildings and large open area \\
\hline the plots are divided by many roads & not compact neighbouring buildings \\
\hline
\end{tabular}

\section{URBAN DESIGN SOLUTION}

The case study area has the following features (Figure 6 and Figure 9):

- The area has a shortage of public spaces, car parking, and facilities;

- There are no support, infrastructures or facilities focused on the river activities such as kayak or canoeing;

- The existent cycling path stops at the front door of the train station building, with no connection with the urban fabric nor with the city centre (Figure 4);

- The greenery is scarce and it is not organized in gardens, parks or other kinds of places for leisure (Figure 8); 
- The cafe is the only commercial space therefore there is a lack of diversity related with cultural, commercial or services activities (Figure 5).

- The river water front is the most important natural element;

- The most relevant landmark in historical and cultural terms is the train station building, which is located at the central part of the case study area;

- There is a granite stone retaining wall which is promoting the existence of two level of the terrain;

- The existent buildings have as maximum number of level, three floors (Figure 7) which is an advantage of this place, that can be classified as a low-density area;

- The view of water front and of the mountains gives to this place a perception of tranquillity.

Cities are very often located near rivers for many long years. The water fronts have played a key role in the development of cities. Among the advantages of the river presence at cities is its contribution for the quality of life of citizens in urban areas. Rivers have also an impact on shaping society, making areas more attractive and providing travel routes for recreation. Another value embodied in a river regarding the urban fabric is the importance for the promotion of an ecological design solution.

For all the previously referred reasons, this urban design project will be to find strategies in order to make a maximum use of access to the Vouga river water front. This idea was presented at the students' team from the first ideas for the final project (Figure 10).

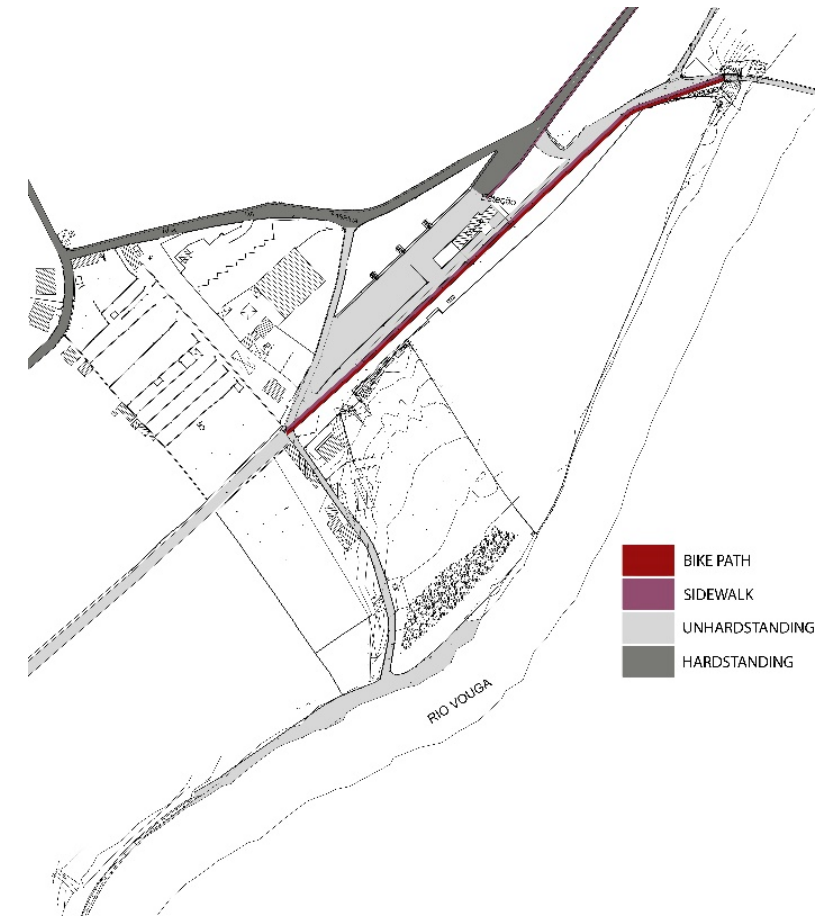

Figure 4. Map of streets surface with the bike path, Train station surroundings, São Pedro do Sul (Portugal).

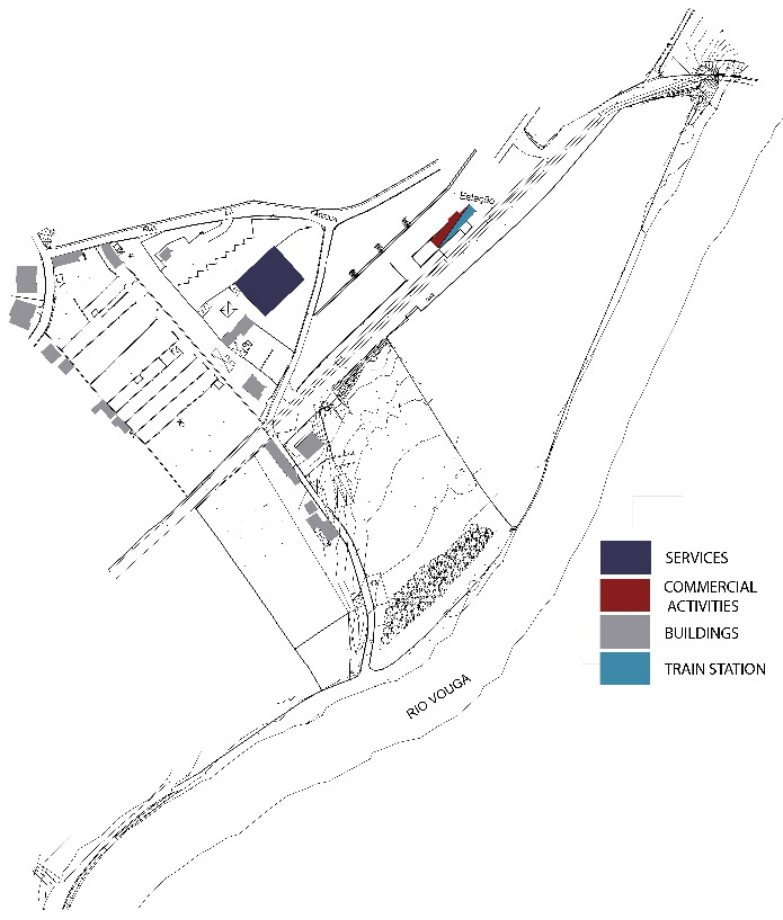

Figure 5. Map of activities per floor, Train station surroundings, São Pedro do Sul (Portugal). 


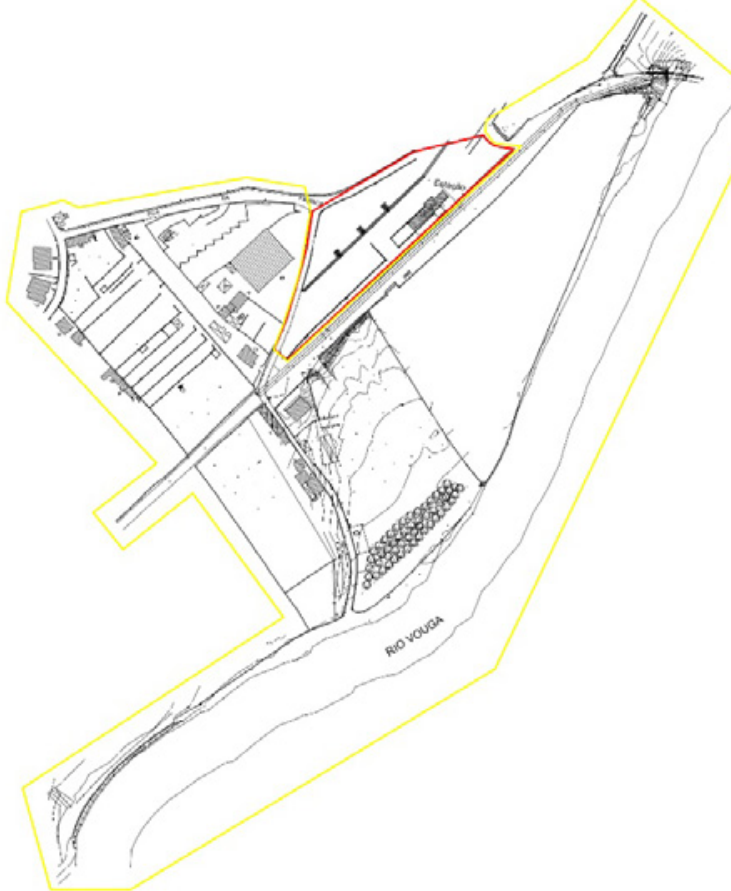

Figure 6. Map of global surface, Train station surroundings, São Pedro do Sul (Portugal).

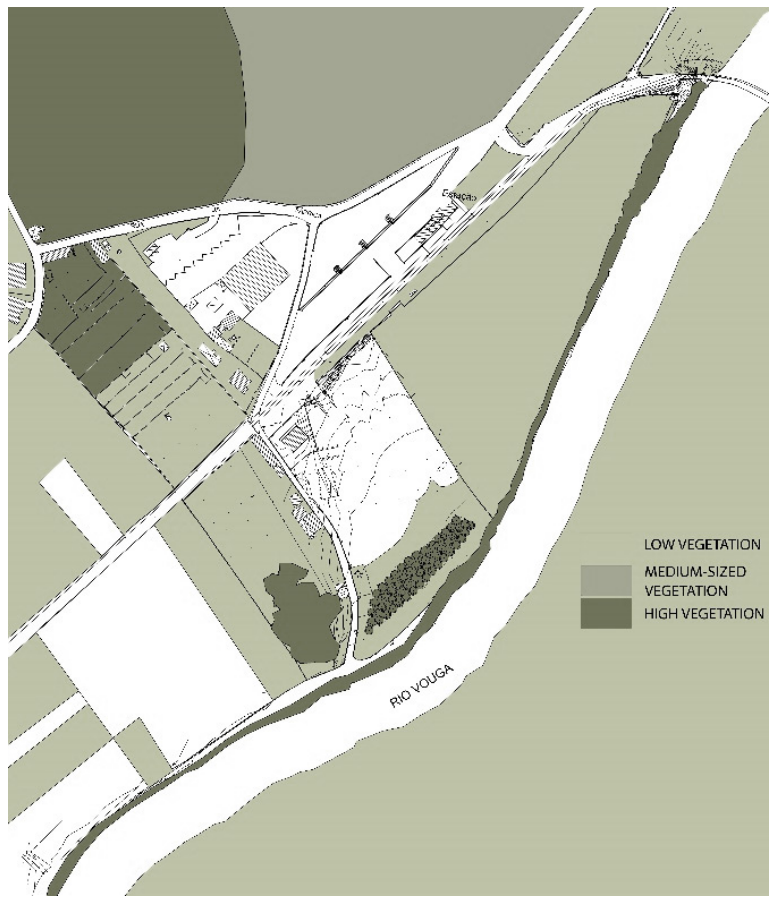

Figure 8. Green spaces, Train station surroundings, São Pedro do Sul (Portugal).

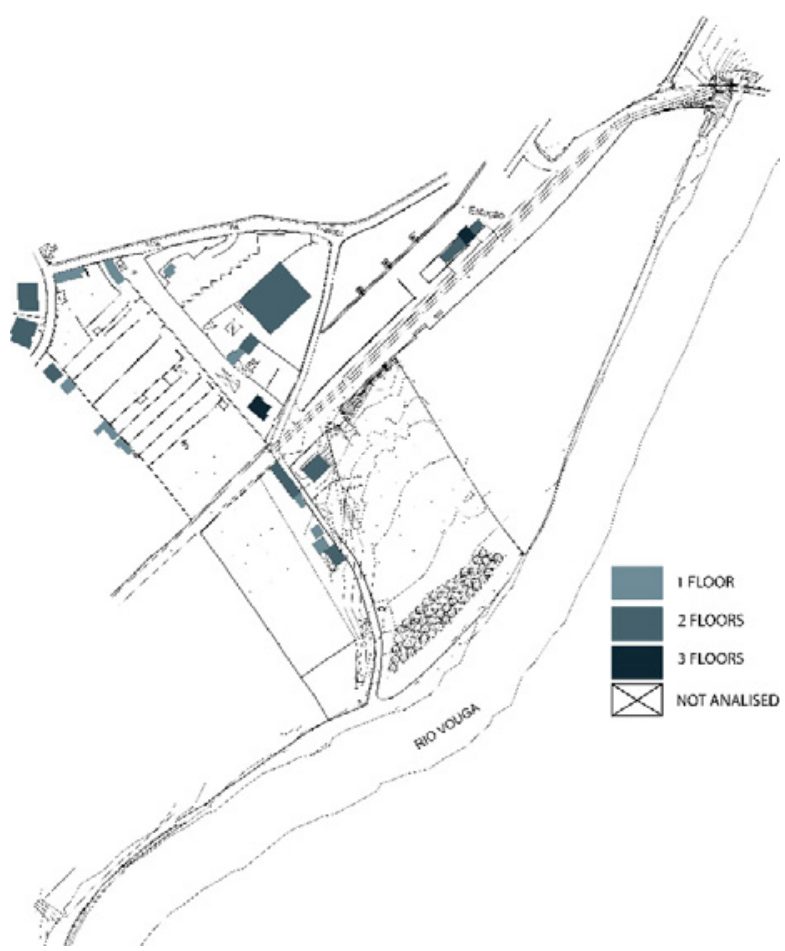

Figure 7. Map of number of floors of existent buildings, Train station surroundings, São Pedro do Sul (Portugal).

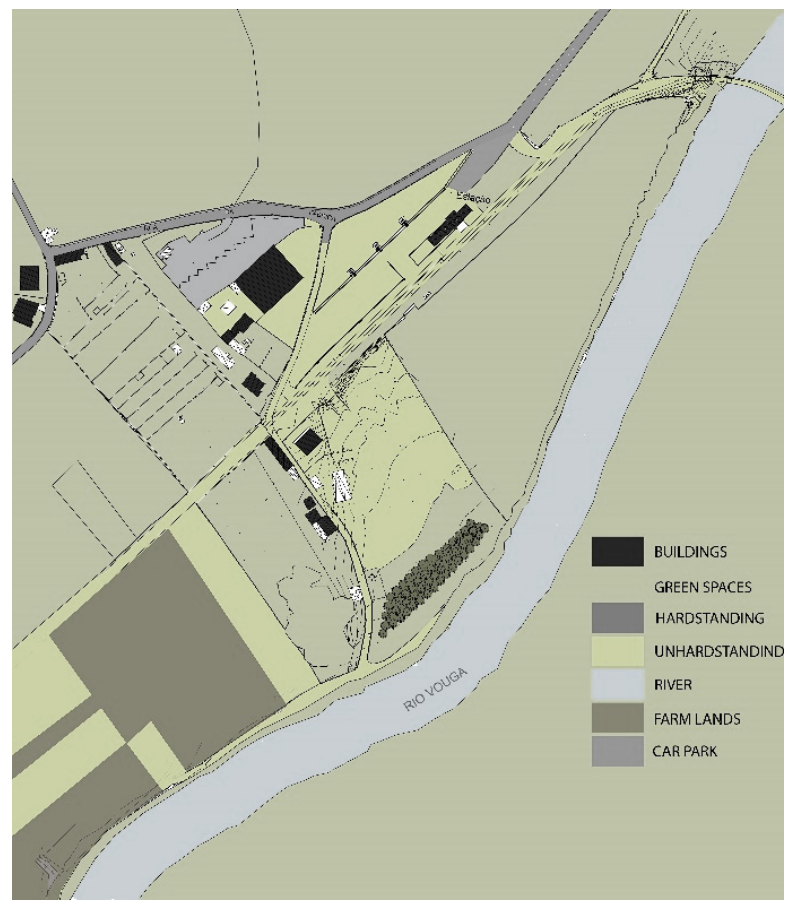

Figure 9. Global map, Train station surroundings, Train station surroundings, São Pedro do Sul (Portugal). 


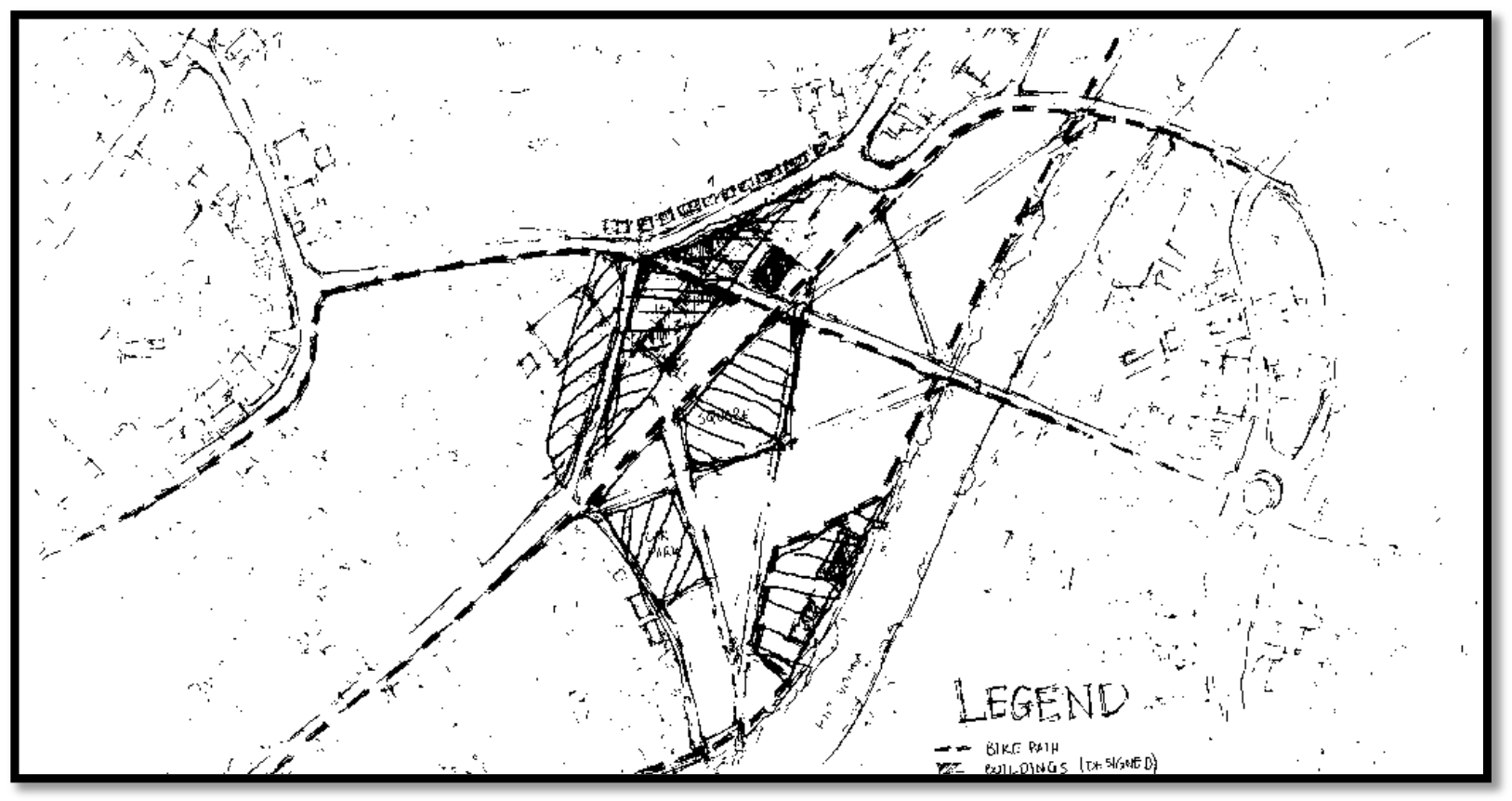

Figure 10. Urban design project: concept of main ideas in order to link the water front with the urban fabric, Train station surroundings, São Pedro do Sul (Portugal).

Another solution to develop the river advantages is the creation of a bike and kayak rental support facility in order to allow the visitor and the inhabitants to practices these sports on Vouga river. This infrastructure will be part of a walkable system network comprising the sidewalks which will be crossing all the case study area. These soft mobility paths will be continuing over the roof of the two main central buildings, with a green roof. These walkable green roofs will be an architectonic innovation not only in the city of São Pedro do Sul but also all over the Viseu region (Figure 11 and Figure 12). The Green surfaces such as the green roofs in the city context are still considered a new field including in the ecological, horticultural or buildings realms. Regarding the urban design process the use of green roofs or surfaces on buildings, is still a surprising and unexpected concept [2]. According to the same author, there are justifiable reasons for the non-priority of greenery or so-called 'ecological' matters in cities, nevertheless, there are non-deniable advantages and benefits coming from the greenery presence in urban spaces.

An iconic proposal is the new bridge for pedestrians and for cyclers over the river in order to reinforce and connect both sides of the river banks. From this bridge is possible to have a nice view over the landscape and over the water (Figure 13 and Figure 14). These new pathways will provide an easy and direct connection between the train station square and the river. The nineteen-century building of the train station was left intact because of its cultural and historical importance as a landmark in the city. It will be used as a meeting and cultural house.

Given that the city of São Pedro do Sul is visited by a lot of tourists because of its thermal baths, this project was focused on the increasing of the potential of Vouga river. To sum up it assumes with its proposals the urban continuity in between the urban fabric and the water front. This urban design solution proposes a huge space for greenery, and a new housing neighbourhood based on singlehouses in order to keep the low-density has an identity feature of the place. The benefits of the greenery at the urban context are very well known, including its contribute to the improvement of property value [3], regarding the rehabilitated buildings, streets and neighbourhood improvements.

The greenery can improve the quality of human experience in cities [4] and they have the ability to become a landmark, promoting the clarification of the urban order, and to point the significance of the places [5]. The amazing view of the mountains make São Pedro do Sul very attractive and the perception of being with nature over the river banks will improve this feeling (Figure 15, Figure 16 and Figure 17). 


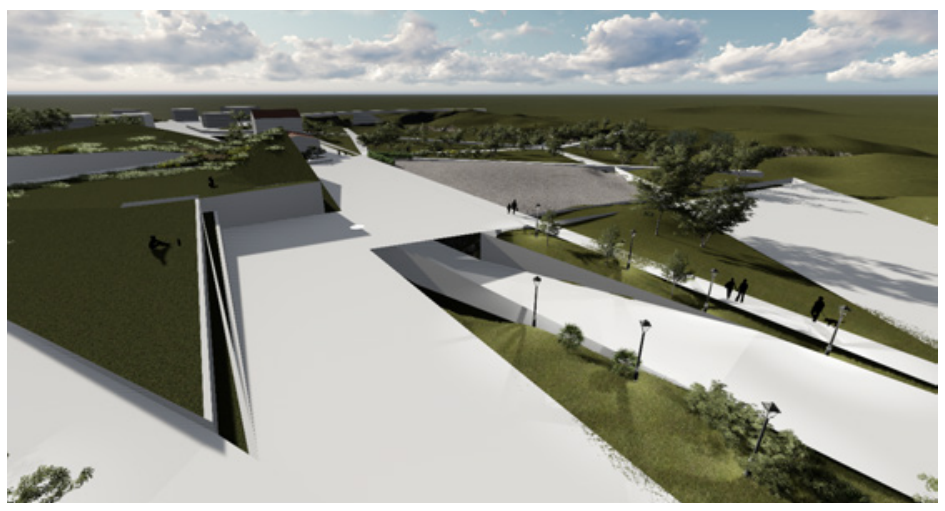

Figure 11. Urban project: General view of the green roof building and the walkable system network.

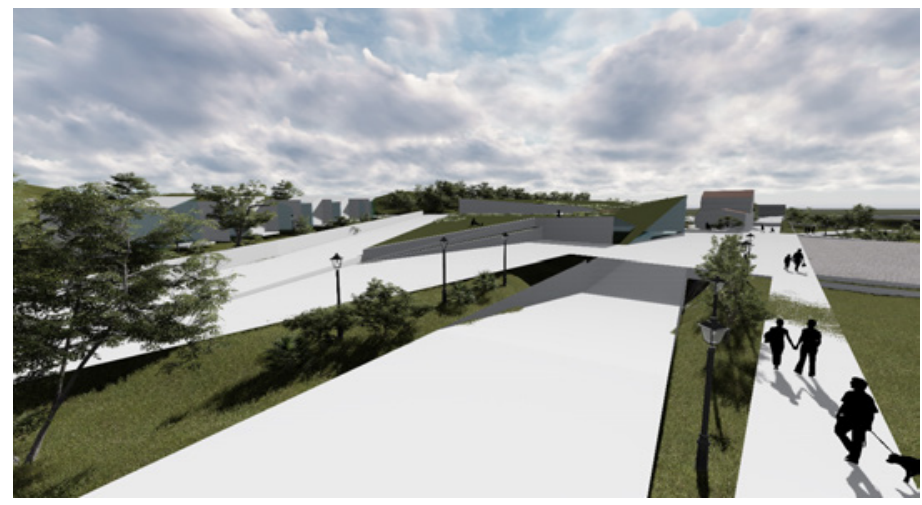

Figure 12. Urban design project: perspective from the bird's eye view of the green roof building add main pavilions, Train station surroundings, São Pedro do Sul (Portugal).

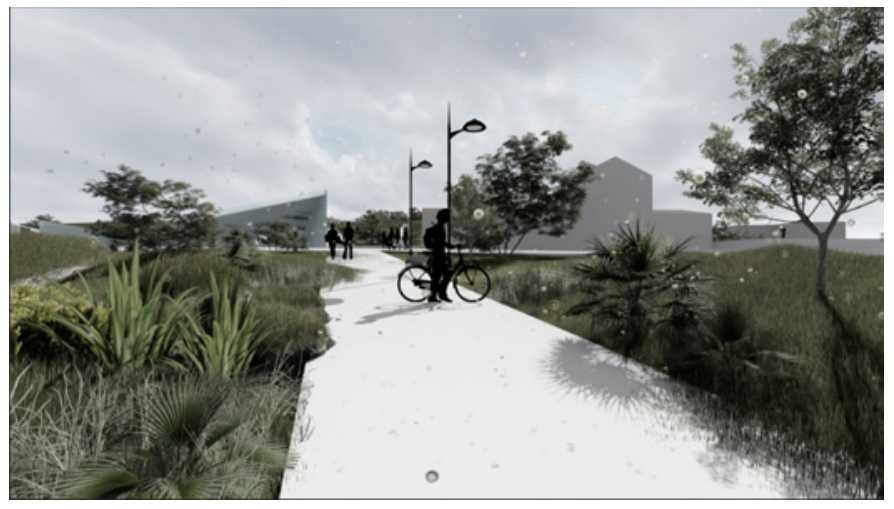

Figure 13. View from the path taken on the case study area with part of the soft mobility system.

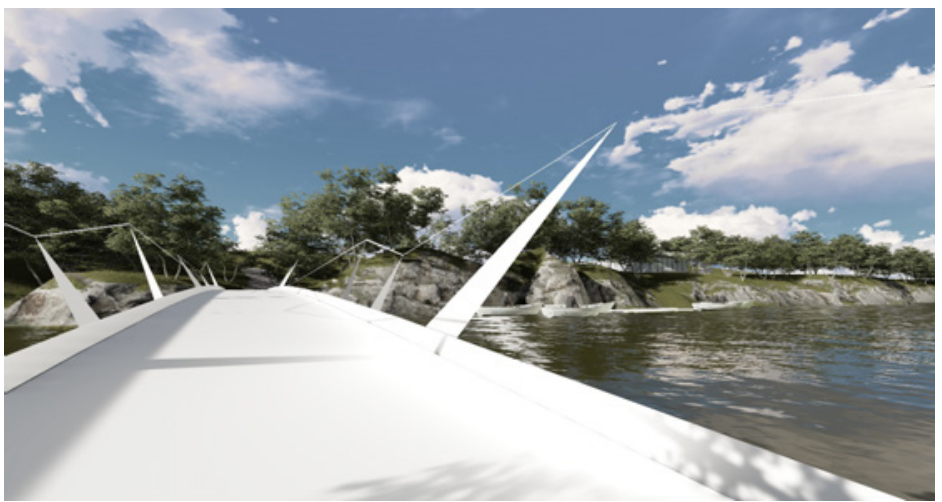

Figure 14. The pedestrian and cycling bridge over the Vouga river: urban project. 


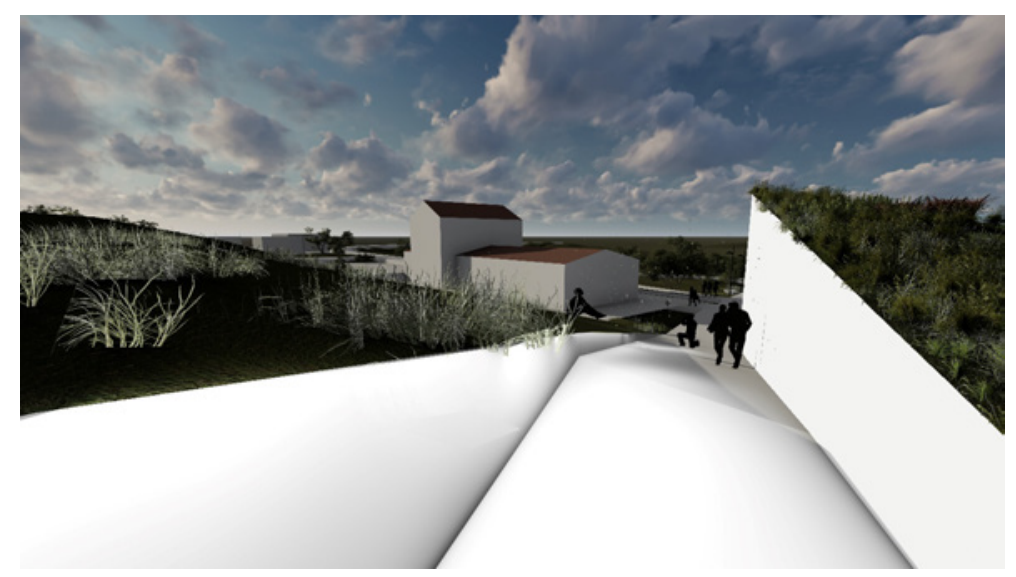

Figure 15. Urban design project: view of the train station building, Train station surroundings, São Pedro do Sul (Portugal).

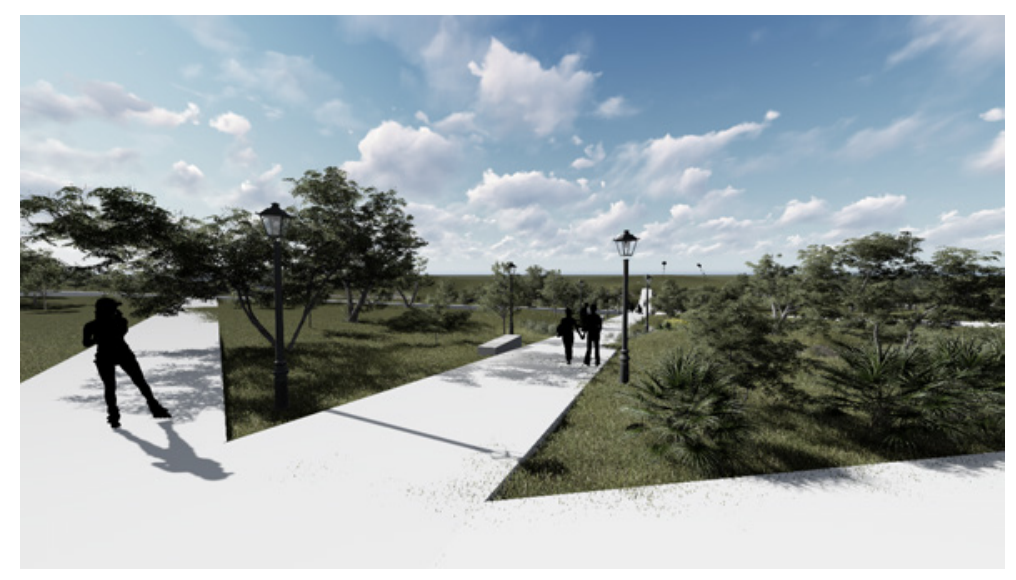

Figure 16. Urban design project: perspective from the path for pedestrians, Train station surroundings, São Pedro do Sul (Portugal).

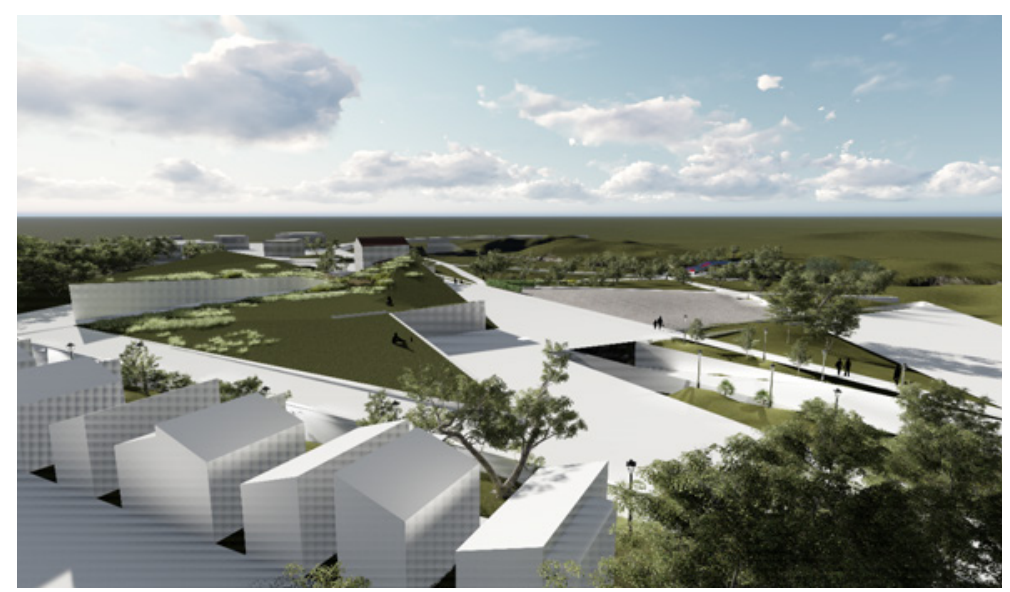

Figure 17. Urban design project: view on the rental housing, Train station surroundings, São Pedro do Sul (Portugal).

\section{CONCLUSIONS}

As this paper aimed to show, the train station surroundings, is a place which needs a deep action of urban improvements and requalification. It has roads in disorder and forgotten plots. However, there is out there a really large potential regarding the Vouga river, the historical building of the train station or the cycling path. São Pedro do Sul is a small city with a good environment for living and also for therapy of skin diseases, given the existence of thermal waters with sulphur, allowing people healing 
their skin problems. There are also historic ruins, the water front and the mountains, making this place a very attractive site for tourists. The presented urban design solutions aimed to improve all these advantages. The project main goal is to be an answer for the needs of inhabitants and visitors. The first step was to organize the existing features of the case study area and giving it new functions with respect to the train station building. Thus, the whole space was organized in different elements with a crucial focus on the public spaces. The projected different parts were designed in a coherent way thanks to simple shapes and to the ecological character. The architecture proposals aimed to be a useful way of improving the quality of life of local community. That's why the project was trying to be a synthesis for the found problems and needs. With this solution, the train station surroundings will be a place that invites businessman, managers of local companies, families, lonely elderly people, friends, tourists and many others. In this sense, is very important rethinking the natural environment development ordering and connecting all the parts of the case study area as a whole places.

Given that humans feel good in nature this proposal aimed to respect the environmental features, throughout ecological architecture and urbanistic strategies. Urban projects should fulfil goals such as security of nature, showing its good aspects and let people use these areas for relax, increasing health and develop interpersonal relationship. The Vouga river gives many possibilities to spend attractive time, such as canoeing, ride a bike and do workout at outside gym. Moreover, these activities let people to use the goods of nature without destroying them. The experience of the referred agreement between the city hall and the university team on behalf of the Urban Planning Unit at the Architecture Studies, giving prizes for the best urban design solution, was a crucial element of success of these proposals. Finally, the main motives for this project were the interactivity in between the place and the community, using the potential of the place. Such as Winston Churchill uses to say "We shape our buildings; thereafter they shape us". In this sense, architecture and urban planning affects the lives of people. That's why is so important to create good places for living able to improve the quality of lives!

\section{ACKNOWLEDGEMENTS}

This publication was supported by the C-MADE, the Centre of Materials and Building Technologies, University of Beira Interior, Covilhã, Portugal, financed by FCT, the Portuguese Foundation for Science and Technology.

\section{REFERENCES}

[1] A. Virtudes, and M. Manso, "Applications of Green Walls in Urban Design," Earth and Environmental Science, no. 44, 2016. IP address: 193.137.97.138; Doi: 10.1088/17551315/44/3/032016

[2] A. Virtudes, "Benefits of Greenery in Contemporary Cities," Earth and Environmental Science, no. 44, 2016. IP address: 193.137.97.138; Doi: 10.1088/1755-1315/44/3/032020

[3] K. Ichihara, and J.P. Cohen, "The New York City property values: what is the impact of green roofs on rental pricing?" Letters in Spatial and Resource Sciences, no. 4, 21-30, 2011.

[4] AA.VV., Introduction to Green Walls Technology, Benefits \& Design, Green roofs for healthy cities, 2008.

[5] J. Jacobs, The Death and Life of Great American Cities, New York: Random House, 1961. 